\title{
Uma análise qualitativa dos conceitos básicos de Astronomia dos professores dos Anos Iniciais do Ensino Fundamental
}

Alisson Henrique Silva alisson000silva@.gmail.com orcid.org/0000-0002-1367-8211 Educação para a Ciência e a Matemática, (PCM/UEM), Maringá, Paraná, Brasil

Renata da Silva Trintin renatatrintin@gmail.com orcid.org/0000-0001-5463-8323 Programa de Pós-Graduação em Educação para a Ciência e a Matemática, (PCM/UEM), Maringá, Paraná, Brasil

\section{RESUMO}

A pesquisa objetivou analisar qualitativamente as noções básicas de Astronomia dos professores atuantes nos Anos Iniciais do Ensino Fundamental de algumas escolas da rede particular de Maringá, PR, por meio de um questionário elaborado pelos pesquisadores. Em sequência, este foi encaminhado para diversos professores. O trabalho pretendeu destacar alguns conceitos exigidos no currículo da etapa selecionada, segundo a legislação municipal, além de relatar alguns conceitos que os professores devem ensinar, a partir das características de suas formações de acordo com as respostas do questionário. Os dados obtidos que foram submetidos a análise de conteúdo (BARDIN, 2000) e divididos em duas Unidades de Significados: a primeira diz respeito ao conhecimento amplo sobre o trabalho que tal professor executa com relação ao conteúdo de Astronomia e à sua formação e a segunda trata de conhecimentos específicos sobre Astronomia. A análise concluiu que nenhum professor teve formação específica na área. Faz-se necessário destacar o pouco conhecimento que os participantes possuem sobre Astronomia com relação a rotação e translação da Terra tanto como relatado no questionário em que foram apresentadas suas respectivas formações, em específico, a formação inicial, considerada fraca, ou até nula, desses profissionais sobre os conteúdos de Astronomia. Entende-se que tal falha de formação de professores reflete diretamente em suas aulas, assim, é recomendável que durante sua formação inicial o licenciando seja inserido em uma análise crítica sobre o ensino de Astronomia e busque superar o senso comum.

PALAVRAS-CHAVE: Astronomia. Formação de Professores. Anos Iniciais do Ensino Fundamental. 


\section{INTRODUÇÃO}

Como apresenta Guellere e Machado (2010) podemos compreender a Pedagogia como uma Ciência tanto prática como teórica que concomitantemente investiga e problematiza a área da Educação de tal forma que, por meio de sua formação, o pedagogo influência de maneira atuante na modificação e construção da sociedade. Por possuir um papel tão importante, se torna fundamental uma formação que abranja um amplo leque de metodologias e que contemplem os mais diversos conteúdos e que, além disso, permita aos pedagogos construir um grande conhecimento por meio dos conteúdos.

Sendo um curso universitário que dispõe de um grande número de opções de atuação profissional, seja em sala de aula ou nas áreas administrativas das escolas, isso acaba se tornando um problema, pois algumas instituições de ensino possuem um pequeno tempo para abordar todos os pontos destacados, o que compromete o aprendizado desses futuros pedagogos. Além disso, observa-se que a área na qual há uma grande defasagem de conteúdo é a de Ciências, como apresenta a fala de uma professora universitária:

[...] pouca carga horária se destina à disciplina de ciências naturais. Deve-se levar em conta que muitos dos docentes que ministram aulas em faculdades $e$ universidades não dominam o assunto, pois não tiveram uma formação adequada em sua formação inicial (GUELLERE; MACHADO, 2010, p. 3).

Embora existam muitos professores universitários que concordam sobre a relevância de uma boa formação referente aos conteúdos científicos, nem estes a possuem.

Destacando a Universidade Estadual de Maringá e a grade curricular do curso de Pedagogia, verifica-se duas componentes curriculares, ambas com 34 horas de duração, que abordam o tema de Ciências em sua elaboração:

a) 3a Série: Metodologia do ensino de ciências: 1a a 4a séries do Ensino Fundamental;

b) 4a Série: Metodologia do ensino de ciências: 1a a 4 a séries do Ensino Fundamental.

Sendo seus objetivos:

Selecionar os conteúdos de Ciências que devem ser abordados em cada série; analisar e refletir sobre os fundamentos teórico-metodológicos para o ensino de Ciências nas séries iniciais do Ensino Fundamental; discutir a instrumentação para o ensino de Ciências; elaborar planejamentos para o ensino de Ciências (Res. 170/05-CEP).

É interessante notar que, por mais que essas matérias abordem de uma forma geral metodologias e didática para o Ensino de Ciências, a própria aprendizagem do conteúdo de Ciências não ocorre, de forma a se esperar que o pedagogo atuante em sala de aula que não possua um grande conhecimento sobre o tópico ou que, talvez, sinta-se despreparado para trabalhá-lo em sala de aula (GUELLERE; MACHADO, 2010).

A realidade da formação de professores para os Anos Iniciais do Ensino Fundamental carece de reflexão sobre a ciência e sobre o seu ensino, provocando uma grande insegurança nesses professores quanto ao desenvolvimento do 
conhecimento científico em sala de aula, resultando em um trabalho pouco ou nada inovador, limitando, em muitos casos, a leitura ou realização de exercícios propostos pelo livro didático que, por melhor que seja produzido, pouco contribui para um primeiro contato atraente da criança com o mundo dinâmico da ciência (BATISTA, 2016).

Um dos tópicos trabalhados no currículo de Ciências nos Anos Iniciais do Ensino Fundamental é a Astronomia, a qual é o foco da nossa pesquisa. Para desenvolvê-la, foi utilizado o seguinte questionamento: "[...] a Universidade prepara o educador para trabalhar o conteúdo de Astronomia nas séries iniciais? Se prepara, como faz?", feito por Guellere e Machado $(2010$, p. 3) em uma pesquisa com alunas do 4 을 ano de licenciatura em Pedagogia.

O trabalho de Batista (2016) identificou que a formação do Pedagogo é completamente voltada para os aspectos metodológicos do ensino e que, concernentemente aos conceitos de Astronomia, há um descaso das instituições de ensino para com esses professores dos Anos Iniciais do Ensino Fundamental, em específico, no estado do Paraná, que não apresenta formação condizente com o proposto nos documentos oficiais. E tal falha, segundo Langhi (2007), influencia os professores devido às suas inseguranças em recorrerem aos livros didáticos como fonte de informações. Ainda no mesmo trabalho, o autor aponta diversos erros conceituais dos livros didáticos.

Sendo assim, por meio de um questionário e analisando os documentos oficiais do município selecionado, buscou-se saber como trabalham os professores já atuantes na educação básica e seus respectivos conhecimentos sobre Astronomia, uma vez que a maioria dos professores analisados das pesquisas anteriormente citadas responderam não terem formação e não se sentirem preparados para trabalharem os conteúdos específicos de Astronomia.

\section{BASES LEGAIS PARA O ENSINO DE ASTRONOMIA NOS ANOS INICIAIS DO ENSINO FUNDAMENTAL.}

Desde a Lei de Diretrizes e Bases da Educação Nacional (LDB, Lei no 4024/61) há ressalvas sobre a quantidade de anos que o Ensino Fundamental completo teria. Nesta Lei é estabelecida a obrigatoriedade de quatro anos para essa etapa que foi ampliada para seis anos após o acordo de Punta Del Este e Santiago, de 1970. Quando em 1971, houve a publicação da nova LDB (Lei no 5692/71) ampliando de seis para oito anos obrigatórios. A mais recente LDB (Lei no 9394/96) não propunha a alteração na quantidade de anos de imediato, mas possibilitou esse aumento, assim como, ocorreu na proposição do Plano Nacional de Educação (PNE), de 2001 (Lei no 010172/01), cuja meta 2 apresentou a possibilidade progressiva desse real aumento de oito para nove anos do Ensino Fundamental. Por fim, em 2005, foi estabelecido na Lei 11.114/05, alterando a LDB de 1996, a obrigatoriedade da matrícula a partir dos seis anos de idade no Ensino Fundamental e, em 2006, a Lei no 11.274/06 ampliou a duração, de oito para nove anos.

Para tal atualização na legislação nacional sobre a educação, a Secretaria de Estado da Educação do Paraná (SEED/PR) constituiu um documento (PARANÁ, 2010) com orientações a fim de acarretar reflexões teórico-metodológicas no processo para reorganizar a Proposta Pedagógica dos Anos Iniciais do Ensino Fundamental. Este contempla crianças dos seis aos dez anos de idade, ou do 
primeiro até o quinto ano do Ensino Fundamental. O documento apresenta as orientações para as seguintes áreas: Alfabetização e Letramento, Arte, Ciências, Educação Física, Ensino Religioso, Geografia, História, Língua Portuguesa e Matemática. Como é do escopo da pesquisa, restringimos ao tópico deste texto que trata das Ciências e em específico da Astronomia.

O documento conta com um resgate histórico que evidencia a preocupação com a matéria de Ciências devido à influência de projetos norte-americanos de desenvolvimento científico na década de 1950 e meados de 1960. Essa preocupação é substituída pela preparação para o trabalho quando a instauração da Ditadura Militar (1964-1985). A disciplina de Ciências não desenvolveria o cidadão crítico ou o pesquisador, mas sim o trabalhador técnico. Fato que influenciou diretamente a formação dos profissionais da educação. A situação só concebeu notável mudança com a redemocratização nos finais dos anos 1980 e início dos anos 1990 gerando críticas a alienação da ditadura (PARANÁ, 2010).

Já entre os anos de 1990 a 2000, a política dos Parâmetros Curriculares Nacionais (PCN) era de constituir a disciplina de Ciências para alcançar uma formação generalista, que se tornou fragmentada. Porém,

\begin{abstract}
A educação científica nos dias atuais, a partir dos Anos Iniciais do Ensino Fundamental, muito além da necessidade de preparar os estudantes para inserção em uma sociedade que baseia cada vez mais seus valores em produtos da ciência e da tecnologia, deve possibilitar o aprendizado dos conceitos científicos escolares capazes de inserir os estudantes no debate social a respeito de ciência e tecnologia e suas implicações (PARANÁ, 2010, p. 47).
\end{abstract}

Para alcançar esses objetivos, além da produção de tecnologia e da ciência gerar produtos, as orientações buscam construir o cidadão com prática social e que consiga argumentar sobre as implicações que a ciência gera. Então, o documento apresenta brevemente sobre o que se deve ensinar, sobre as teorias que se deve abordar na faixa etária de seis a dez anos, além de que estas estão imersas em uma história que não pode ser ignorada, constituindo uma ferramenta importante para o ensino de Ciências (PARANÁ, 2010). E especificamos aqui as "grandes áreas" sobre as noções de Astronomia:

a) Sistema de mundo heliocêntrico, porque

Mesmo com a superação do modelo geocêntrico no âmbito da investigação científica, pesquisas sobre as concepções prévias de estudantes dos anos iniciais apontam que é notória a percepção do movimento dos Astros conforme o modelo geocêntrico. A observação é muito clara e contundente: o Sol nasce e se põe todos os dias. Desta forma, o Sol é que se move pelo céu (PARANÁ, 2010, p. 53).

b) Sistema Solar, porque

[...] pode contribuir para o entendimento das ocorrências astronômicas como fenômenos da natureza; dos movimentos celestes, dinâmica do sistema solar, rotação e translação dos planetas e satélites; dos astros que constituem o sistema solar e suas características; do tamanho proporcional dos planetas e sua distância relativa; dos satélites naturais, movimentos relativos da Lua; do Sol como fonte de energia para a manutenção da vida na Terra (PARANÁ, 2010, p. 53). 
Sabendo dessas orientações, recorremos à documentação municipal. 0 currículo da Educação Infantil e Anos Iniciais do Ensino Fundamental da cidade de Maringá (MARINGÁ, 2012) é um documento extenso e que começou com trabalhos dos profissionais da educação desde 2006. O currículo municipal sempre se baseou em documentos estaduais e federais para a própria constituição, e ainda se apresentam como Pedagogia Histórico-Crítica. O currículo trata da Educação Infantil, do Infantil 1 ao 5, e da Educação Fundamental nas matérias: Arte, Ciências, Educação Física, Ensino Religioso, Geografia, História, Língua Portuguesa e Matemática, ambos do 1음 ao 5 ano.

Sendo os Conteúdos Estruturantes para as Ciências: (a) Sistema Solar; (b) Planeta Terra; (c) Fontes de Energia; (d) Corpo humano; (e) Seres Vivos e Ambiente. Focaremos no (a) Sistema Solar, cujos conhecimentos específicos foram selecionados pelos pesquisadores devido ao escopo da pesquisa e estão descritos no Quadro 1:

Quadro 1 - Apresentação de alguns conteúdos específicos sobre as noções de Astronomia relacionados aos Anos Iniciais do Ensino Fundamental

\begin{tabular}{|c|c|}
\hline Anos & Conteúdos Específicos \\
\hline 1 운 & Movimento de rotação - Dia e noite (movimento aparente). \\
\hline 20 & $\begin{array}{l}\text { Movimento aparente do Sol - nascente e poente; } \\
\text { Projeção da sombra. }\end{array}$ \\
\hline 3 운 & $\begin{array}{c}\text { Rotação terrestre (duração aproximada); } \\
\text { Observação das sombras ao longo do dia e do ano. }\end{array}$ \\
\hline 40 & $\begin{array}{l}\text { Sistema Solar; } \\
\text { Outros corpos celestes: iluminados - satélites naturais (lua) e } \\
\text { artificiais, planetas, asteroides e cometas - e luminosos } \\
\text { (estrelas); } \\
\text { Movimento de rotação e translação - dias e noites, anos e } \\
\text { estações do ano. }\end{array}$ \\
\hline 5 운 & $\begin{array}{l}\text { Teoria de formação do universo; } \\
\text { Teoria do Big-Bang; } \\
\text { Origem da Terra; } \\
\text { Fases da Lua; } \\
\text { Eclipses. }\end{array}$ \\
\hline
\end{tabular}

Fonte: Adaptado de Maringá (2012).

Como explicitado no Quadro 1 e nos PCN, os conteúdos que devem ser trabalhados nos Anos Iniciais do Ensino Fundamental abordam questões sobre os componentes e aspectos do Sistema Solar, assim como os movimentos identificados do planeta Terra e suas respectivas consequências. Tais documentos em conjunto com a categorização das Unidades de Significado e de Registro serviram de orientação para a pesquisa e para confecção das perguntas do questionário.

\section{METODOLOGIA}

Considerar-se-á a pesquisa de cunho qualitativo devido à nossa busca para interpretar os fenômenos não quantificáveis, sendo que esse tipo de estudo permite que sejam atribuídos significados sobre as ações do sujeito. 
O questionário foi elaborado tendo em vista o exposto no Quadro 1 e em trabalhos como Langhi (2007) e Batista (2016) que evidenciam os conteúdos que devem ser abordados em sala de aula e as singularidades dos livros didáticos e dos professores que refletem no ensino desses conteúdos.

Em 2017, após a pesquisa e construção do questionário, alguns colégios particulares foram visitados a fim de entregar esse instrumento. A escolha dos ambientes de ensino se fez devido à acessibilidade conquistada por contatos de terceiros. Em todos os colégios, explicitaram-se os objetivos da pesquisa, bem como as devidas considerações sobre o resguardo das identificações, tanto dos participantes como das instituições que forem citadas no questionário. A seguir, estipulou-se um prazo de sete dias para que os questionários fossem respondidos e devolvidos. A aceitação da proposta não foi integral, porém, conseguimos um grupo conforme apresenta o Quadro 2:

\begin{tabular}{|c|c|c|c|}
\hline \multirow[b]{2}{*}{ Professor } & \multicolumn{3}{|c|}{ Dados } \\
\hline & Idade (Anos) & Gênero & $\begin{array}{c}\text { Formação/Ano de } \\
\text { Conclusão/Modalidade }\end{array}$ \\
\hline P1 & 48 & Feminino & Pedagogia/1990/Presencial \\
\hline P2 & 26 & Feminino & $\begin{array}{c}\text { Letras/2005/Presencial } \\
\text { Pedagogia/Cursando/EAD }\end{array}$ \\
\hline P3 & 50 & Feminino & Letras (PT/EN)/2004/Presencial \\
\hline P4 & 35 & Feminino & Pedagogia/2006/Presencial \\
\hline P5 & 27 & Feminino & Pedagogia/2012/Presencial \\
\hline P6 & 34 & Feminino & Pedagogia/2006/Presencial \\
\hline P7 & 40 & Feminino & $\begin{array}{c}\text { Administração/2007/Presencial } \\
\text { Pedagogia/2011/Presencial }\end{array}$ \\
\hline P8 & 24 & Feminino & Pedagogia/2004/Presencial \\
\hline P9 & 40 & Feminino & $\begin{array}{c}\text { Licenciatura em } \\
\text { História/2001/Presencial } \\
\text { Direito/Cursando/Presencial }\end{array}$ \\
\hline
\end{tabular}

Fonte: Autoria própria (2017).

As ferramentas da análise de conteúdo, de acordo com seus procedimentos viabilizam a sistematização na descrição dos conteúdos das mensagens e permitem a produção de uma inferência (BARDIN, 2000). Para tal, seguimos os seguintes procedimentos:

a) Pré-análise: em um primeiro momento, foram avaliadas as respostas dos questionários das professoras da rede particular de ensino, para a constituição de um corpus (conjunto dos documentos que serão submetidos a análise);

b) Exploração do material: os grupos da pesquisa foram delimitados, priorizando as unidades de significado segundo a reunião de questões estabelecidas no questionário e, posteriormente, unidade de registro;

c) Categorização: as unidades que constituem o Quadro 3 foram separadas e organizadas. 
Quadro 3 - Caracterização das Unidades de Significados e Registro

\begin{tabular}{c|c}
\hline $\begin{array}{c}\text { Unidades de Significado } \\
\text { (US) }\end{array}$ & Unidades de Registro (UR) \\
\hline Miscelânea & Conteúdos Trabalhados; \\
& $\begin{array}{c}\text { Formação para o Ensino de Astronomia; } \\
\text { Importância da Astronomia; } \\
\text { Astrologia. }\end{array}$ \\
\hline Noções de Astronomia & Estações do ano; \\
& Movimento da Terra; \\
& Lua; \\
& Sistema Solar; \\
& Pontos Cardeais. \\
\hline
\end{tabular}

Fonte: Autoria própria (2017).

Em relação às Unidades de Significado Miscelânea (doravante US): no item (a) foram analisados os conteúdos que as professoras afirmam trabalhar em suas aulas; no item (b) almejou-se identificar a formação específica ou não sobre Astronomia e se as professoras consideram terem domínio sobre o assunto; no item (c) verificou-se a visão das professoras sobre tal ciência e sua aplicabilidade na sociedade; item (d) pretendeu-se pontuar as concepções filosóficas das professoras sobre o tópico e se há diferenciação dele com a Astronomia.

No tocante às US Noções de Astronomia, buscou-se identificar as concepções das professoras de acordo com conceitos estabelecidos na comunidade científica: no item (a), os aspectos que definem as estações do ano; no item (b), percepção dos movimentos da Terra e o movimento relativo; no item (c), características da Lua com suas fases e aparente sombra; no item (d), constituição do Sistema Solar; no item (e), relação do posicionamento dos Pontos Cardeais com o nascer e o pôr do Sol.

Com base nas características das Unidades de significados supracitadas, formulou-se a análise que segue na sessão seguinte.

\section{RESULTADOS E DISCUSSÕES}

Dada a categorização das US e Unidades de Registro, doravante UR, explorouse a maior quantidade de conteúdos que apresenta o documento Maringá (2012), de forma a explicitar as concepções de Astronomia de algumas professoras, as quais não apresentam uma visão aceita pela comunidade científica atualmente. Fato que corrobora com o trabalho de Langhi (2007), o qual apresenta as incongruências nos livros didáticos.

De maneira geral, para a análise da US Miscelânea:

a) Conteúdos Trabalhados: Em sua maioria, as falas das professoras remetem a um discurso condizente parcialmente aos encontrados no Quadro 1, em específico: Sistema Solar e os seus planetas. Em especial as professoras P4 e P7 apresentam que os conteúdos de Astronomia são trabalhados na matéria de Geografia e somente a professora P5 cita a formação do Universo como um conteúdo a ser trabalhado. 
As professoras $\mathrm{P} 3$ e $\mathrm{P} 5$ foram as únicas a citarem a Lua e suas fases, sendo que somente a P3 acrescenta o conteúdo de eclipses. Os tipos de movimentos da Terra são expostos pelas professoras P3, P5 e P8.

Os conteúdos de projeção de sombra, movimento aparente do Sol, origem da Terra e asteroides e cometas não são lembrados pelas professoras, mesmo aquelas que trabalham com os respectivos anos que o documento (MARINGÁ, 2012) recomenda serem trabalhados.

b) Formação para o Ensino de Astronomia: A maioria das professoras não se sente preparadas para abordar esse conteúdo, pois elas alegam que sua formação não foi adequada. Porém, destacam-se as falas das professoras P2 e P7 que, em relação ao conteúdo dos Anos Iniciais do Ensino Fundamental, alegam a simplicidade do conteúdo e mesmo sem possuírem uma formação especifica se sentem preparadas para trabalharem em sala de aula.

P2 - "Para o ensino fundamental I, teria sim, me sinto preparada".

P7 - "Na proposta oferecida pela escola sim. Pois esse tema e aplicado nas atividades de Geografia de uma forma bem simples, focado nos astros, climas, universo e natureza etc.".

Mesmo as professoras P2 e P7, afirmando a sua capacidade de ensinarem tal assunto para determinado nível, encontra-se divergências nas respostas das perguntas conceituais que serão analisadas mais adiante.

A professora P3 afirma com somente um "Sim.", estar preparada para trabalhar esse conteúdo, porém não justifica a própria fala nem responde às perguntas conceituais.

c) Importância da Astronomia: Nenhuma das professoras considera a Astronomia prejudicial para o desenvolvimento da criança. Em geral elas argumentam que a Astronomia serve para a criança se situar no Universo, com as relações de dia e noite e estações do ano, além da geração de tecnologia. Vale ressaltar que a professora P9 destaca a criticidade do ser exposto no seguinte trecho: " [...] Conhecer o meio que nós cerca faz-nos ter uma consciência de quem somos e possibilita agirmos de forma consciente, nesse meio".

Apesar de todas concordarem sobre a importância da Astronomia, há má interpretação do que ela seria no cotidiano, especificamente em comparação com os conteúdos de Geografia, como as mudanças climáticas, fuso horário e localização geográfica.

d) Astrologia: As professoras P3, P5, P7 e P9 concordam que a falta de cientificidade culmina para a falta de validade, apesar de P7 comentar do gosto pessoal de cortar os cabelos na Lua Crescente.

As professoras P2 e P4 não explicitam a justificativa, mas dizem não acreditar na influência dos astros como diz a Astrologia. A P6 diz não saber e a P8 descreve sucintamente o que seria Astrologia para alguns estudos, como a relação direta dos astros com a personalidade.

Destacamos a seguinte fala:

P1 - "Sem sombra de dúvida a astronomia está diretamente ligada ao desenvolvimento do ser humano. Como estamos acostumados a ouvir: no sexo da 
ç̧a (criança), na melhor lua para o crescimento do cabelo, combinação de signos etc.".

Apesar de a maioria das pessoas dizer não validar a Astrologia, a professora P1 tanto valida quanto apresenta a confusão entre os termos Astrologia e Astronomia.

Para a análise da US Noções de Astronomia:

a) Estações do ano: As professoras P2, P6 e P7 compreendem as estações do ano devido a inclinação do eixo de rotação da Terra. Somente a professora P8 apresenta uma justificativa clara, porém errada, acreditando que as estações do ano ocorrem devido à proximidade da Terra e o Sol.

b) Movimento da Terra: Aparentemente todas as professoras concordam com os movimentos de rotação e translação da Terra, porém não conseguem justificar o estado de repouso dos corpos que estão na Terra apesar dela se movimentar, à exceção da professora P5, como segue:

P5 - "Nós não percebemos a Terra girando porque também estamos em movimento".

É necessário destacar que a professora P7 corrige a velocidade de translação da Terra da ordem de $10^{4} \mathrm{~km} / \mathrm{h}$ para "aproximadamente $147.100 .000 \mathrm{~km} / \mathrm{h}$ ".

c) Lua: Há concordância geral que a Lua possui uma superfície irregular, porém somente as professoras P2, P6 e P7 compreendem que as fases da Lua dependem do nosso referencial. Em específico, a P6 reconhece que há diferença em ver a Lua em diferentes hemisférios.

d) Sistema Solar: Somente as professoras P2, P5 e P7 apresentaram justificativa válida sobre as classificações de planetas rochosos e gasosos. A professora P9 diz não saber sobre a existência dessa classificação, as demais apresentam justificativas vagas ou não justificam.

e) Pontos Cardeais: As professoras P1, P2, P7 e P9 justificam de maneira satisfatória a não obrigatoriedade dos pontos cardeais Leste e Oeste corresponderem ao nascer e pôr do Sol respectivamente.

A única professora que afirma que o nascer e o pôr do Sol ocorrem, respectivamente, no Leste e Oeste é a P8.

Na questão da formação dos professores, como assinalado anteriormente no trabalho, as professoras P2, P3 e P7, apesar de nenhuma formação específica na área, dizem-se em condições adequadas para trabalhar o conteúdo por considerarem-no simples. Porém, P3 não respondeu as questões conceituais e ambas, P2 e P7, não responderam satisfatoriamente os itens que envolvem concepções de movimento da Terra, rotação e translação, com relação aos corpos que estão na Terra e que estão em repouso nela. Ressaltamos que esse conteúdo é recomendado pelo documento Maringá (2012) para ser trabalhado no 1으, 3o e 4o ano do Ensino Fundamental.

$\mathrm{Na}$ questão 2 da segunda parte, foi pedido para que as professoras assinalassem verdadeira ou falsa e justificassem a afirmativa: Apesar de não percebermos, a Terra gira em torno do Sol com uma velocidade enorme, na ordem de $10^{\wedge} 4 \mathrm{~km} / \mathrm{h}$. É interessante ressaltar que a professora $\mathrm{P} 2$ diz não compreender a nomenclatura $\left(10^{\wedge} 4 \mathrm{~km} / \mathrm{h}\right)$ e ainda expõe uma das maneiras de se calcular a 
velocidade de rotação da Terra utilizando as horas que compõe um dia ( $24 \mathrm{~h}$ ) e a circunferência da Terra dada pela linha do Equador. Apesar de não reconhecer a nomenclatura, existe certa confusão no que se diz respeito a rotação e translação da Terra porque mesmo a questão abordando o movimento de translação da Terra, a professora justifica dessa maneira: "[...] Sei, a velocidade da Terra pode ser calculada dividindo a circunferência do Equador por 24 (quantidade de horas por dia)".

Já a professora P7 responde a questão 2 da segunda parte da seguinte maneira: "Este movimento de translação atinge uma velocidade de aproximadamente $147.100 .000 \mathrm{~km} / \mathrm{h}^{\prime \prime}$, informação que corresponde ao raio da Terra medida em quilômetros. Essa informação é de fácil acesso como verificado no site de busca Google, pesquisando a seguinte frase: "qual a velocidade de translação da Terra". O que nos leva a supor que a professora utilizou-se de pesquisa para a execução do questionário, prática que solicitamos que não ocorresse, principalmente quando o dado apresentado pela professora não corresponde ao tratado na questão.

No tocante à análise da questão 3 da segunda parte, foi solicitado que as professoras justificassem a afirmativa: A rotação da Terra ao redor de si ocorre em uma velocidade perto de $1700 \mathrm{~km} / \mathrm{h}$. Isso quer dizer que precisamos ultrapassar essa velocidade no sentido contrário à rotação da Terra caso queiramos nos deslocar de uma cidade a outra. A professora P7 assevera que a informação dada é sem sentido, porém, não apresenta justificativa para tal afirmação e ainda relata que o movimento de rotação da Terra "[...] é o responsável pela contagem dos dias, meses e anos". Já a professora P2 apresenta um erro conceitual afirmando que não sabe justificar a questão 3 , porém, explica da seguinte maneira: "[...] Só me lembro que li que um avião no sentido contrário ao movimento da rotação da Terra, chega mais rápido", evidenciando uma concepção errônea sobre o assunto. Deve-se reconhecer tal erro como relativamente comum, uma vez que tal noção se enquadra em uma concepção alternativa pré-galileana e antropomórfica afirmada em Valadares (1995).

Considerando a questão 8, a afirmativa que deveria ser justificada foi: O nascer do Sol sempre ocorre exatamente no ponto cardeal Leste e o pôr do Sol no Oeste. Destaca-se a resposta da professora P7 pelo fato de ser a única cuja resposta foi avaliada prontamente como errada, pois ela concorda que o Sol nasce no ponto cardeal Leste e se põe no Oeste. Porém, é sabido que o Sol não acompanha exatamente os pontos cardeais devido a translação da Terra e o eixo de rotação. Uma possibilidade de justificar esse erro está no fato de que alguns livros didáticos apresentam o mesmo erro quando explicam os procedimentos para a identificação dos Pontos Cardeais, como preconiza Langhi (2007).

Em um panorama geral, o gráfico (figura 1) abaixo consta as questões que foram respondidas corretamente segundo suas justificativas $(A)$, as questões que foram respondidas erradas segundo as suas respectivas justificativas (B) e as questões que não possuem justificativas ou as que possuem justificativas vagas como: não sei, nunca estudei, discordo, concordo, penso assim (C). 
Figura 1 - Relação das respostas das professoras

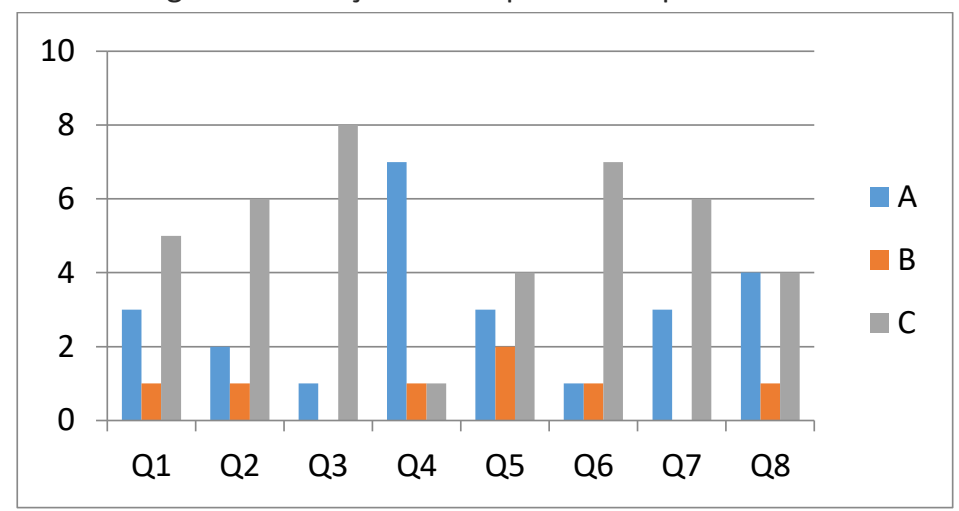

Fonte: Autoria própria (2017).

Os dados apresentados no gráfico acima mostram uma preferência das professoras em dar respostas vagas ou não justificá-las, do que buscar uma justificativa coerente em relação ao que foi assinalado como respostas, podendo indicar, em segundo plano, a baixa taxa de erros.

Entende-se que quando as alternativas exigem interpretação além do conhecimento superficial do conteúdo, a taxa de acerto é baixa. Assim como as questões 3, sobre a rotação da Terra como citado anteriormente, e 6 (quando a Lua está na fase Crescente sua parte iluminada parece a letra " $C$ " para o Hemisfério Sul e o contrário para o Hemisfério Norte, "J") que necessitam de uma interpretação sobre uma aplicação no cotidiano, sendo a questão 3 com relação ao movimento de rotação da Terra e na questão 6 as diferenças de observação da Lua Crescente nos distintos hemisférios.

O gráfico mostra uma alta taxa de acerto na questão 4 (A Lua possui a superfície lisa e regular, e reflete a luz do Sol), justificando-se pelo conhecimento das professoras acerca das crateras da Lua. O único erro encontrado na fala da professora P6: "A lua tem [...] crateras e não reflete a luz do sol". Fato que nos leva a inferir a falta de conhecimento acerca das características da Lua, como ela não ter luz própria e somente ser possível sua visualização da Terra devido à reflexão da luz do Sol.

Na questão 9 pedimos que as professoras desenhassem o Sistema Solar e buscassem manter a noção sobre as proporções sobre os elementos que o compõem. As professoras P1 e P3 não realizam essa atividade. Nenhuma das professoras representou os anéis de Urano nem o cinturão de asteroides ou mesmo a presença do planeta-anão Plutão, reforçando a ideia que o Sistema Solar é composto somente pelo Sol e pelos oito planetas (Mercúrio, Vênus, Terra, Marte, Júpiter, Saturno, Urano e Netuno). Outras concepções acerca da constituição do Sistema Solar podem ser internalizadas conforme são apresentadas nos livros didáticos de maneira simples e incompleta, conforme é mostrado por Langhi (2004).

A professora P9 apresenta o desenho mais completo (Figura 2), o qual contém os oito planetas de tamanhos aproximados e Saturno com seus anéis, o Sol em tamanho maior comparado aos planetas. A Lua, os asteroides e meteoros estão menores que os planetas e o cometa de tamanho próximo dos planetas, porém os 
asteroides não aparentam estar orbitando um planeta e os meteoros estão situados fora da atmosfera terrestre. Segue a imagem:

Figura 2 - Desenho esquemático do Sistema Solar da professora P9 com ajuste de brilho

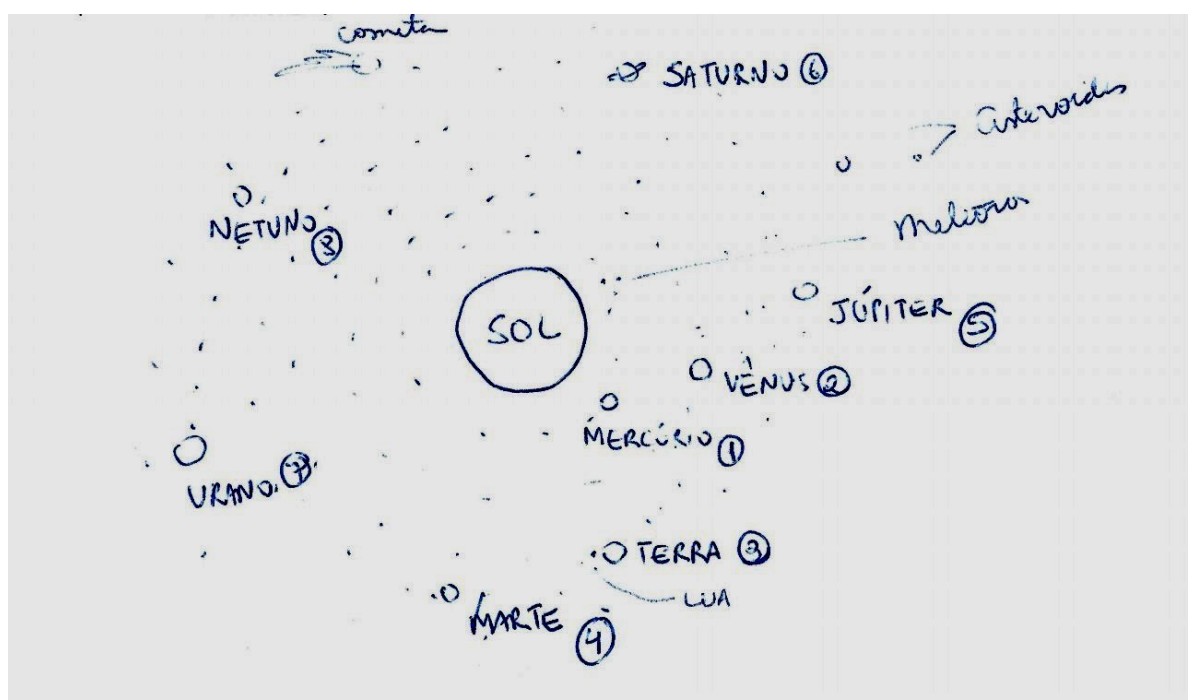

Fonte: Retirada das respostas do questionário da professora P9

É inquestionável que é o desenho que mais contém elementos do Sistema Solar, no qual as órbitas são circulares em torno do Sol e os planetas foram desenhados em suas respectivas órbitas, porém não estão alinhados como os desenhos das professoras a seguir. Fato que pode sugerir uma noção que os planetas transladam alinhados em torno do Sol, gerando erro conceitual, uma vez que os planetas possuem diferentes velocidades de translação.

Em comparação com P9, como mostra a Figura 3, a professora P8 desenhou o Sol maior em comparação aos outros elementos, em sequência a Lua como segundo maior, seguido pelos planetas todos com o mesmo tamanho.

Figura 3 - Desenho esquemático do Sistema Solar da professora P8
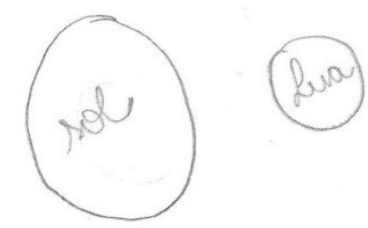

Fonte: Retirada das respostas do questionário da professora P8

Faz-se notório que a imagem apresenta uma noção de que os planetas possuem praticamente o mesmo tamanho e de que a Lua está localizada próxima ao Sol e provavelmente desconexa da Terra.

O único desenho, Figura 4, que possui diversas cores para representar os elementos do Sistema Solar foi produzido pela professora P6. 
Figura 4 - Desenho esquemático do Sistema Solar da professora P6

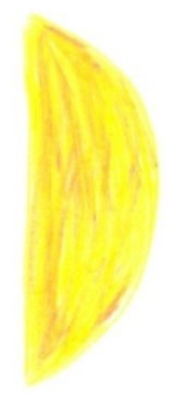

Fonte: Retirada das respostas do questionário da professora P6

Aparentemente, este informante seguiu um certo padrão para as cores dos planetas, onde os planetas próximos ao Sol possuem cores ditas quentes e quanto mais se afasta do Sol os planetas recebem cores mais escuras ou as cores ditas frias. Porém, não há referência sobre quais planetas são, nem suas órbitas, nem ao menos a Lua.

As professoras P5 e P7 apresentam desenhos semelhantes (Figura 5): identificação dos elementos, o Sol como maior astro, Vênus maior que a Terra, Júpiter como o maior dos planetas e a falta de perspectiva nos anéis de Saturno.

Figura 5 - Desenho esquemático do Sistema Solar da professora P5 e P7 respectivamente
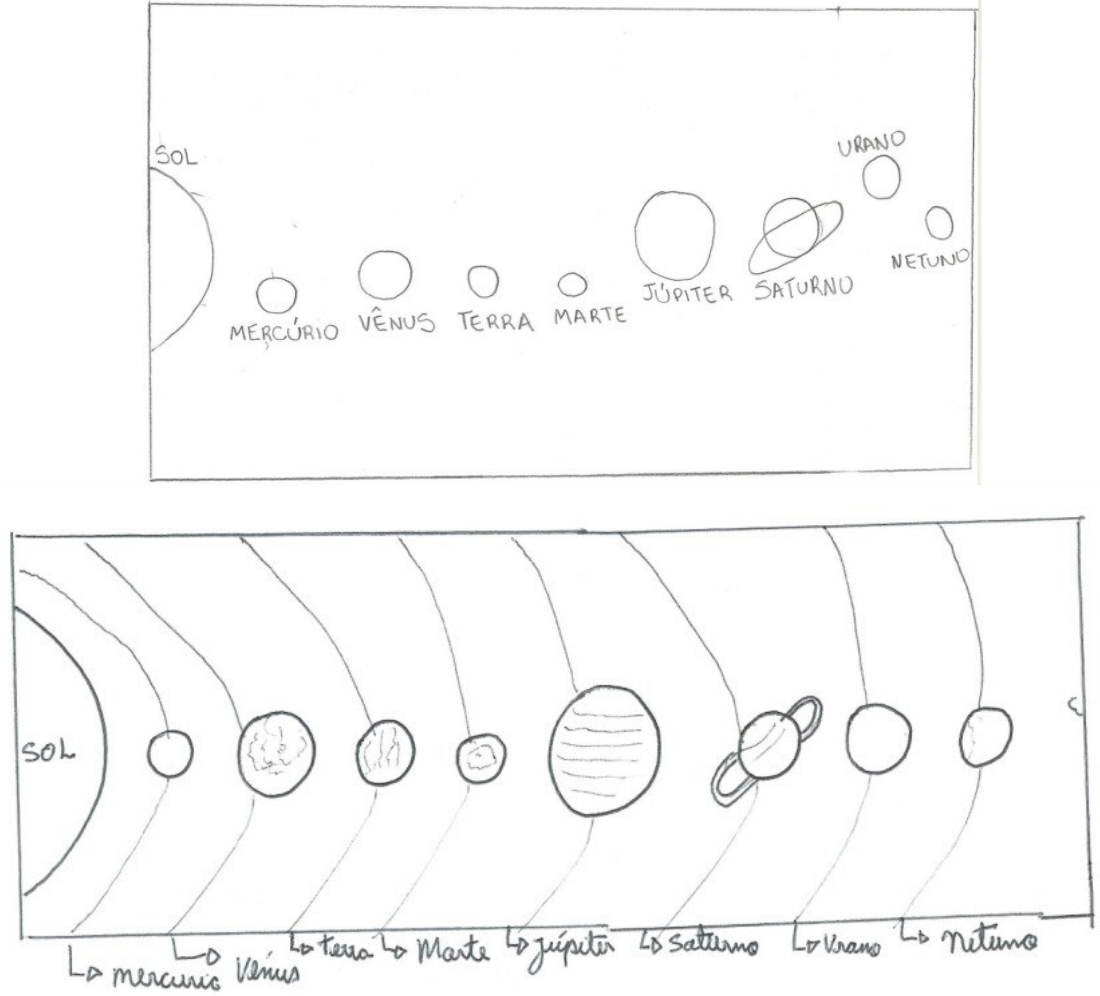

Fonte: Retirada das respostas do questionário da professora P5 e P7 respectivamente

Conclui-se, por meio dos dados gerados pelo questionário que muitas professoras não se sentem preparadas para trabalhar Astronomia nos Anos Iniciais 
do Ensino Fundamental e não receberam a devida formação para tal. O que explicita a falta de conteúdos específicos durante a formação tanto inicial quanto continuada. É visível que para uma melhor formação, o pedagogo poderia ter maior contato em sua graduação com conteúdos específicos, resultando em um profissional menos generalista.

\section{CONSIDERAÇÕES FINAIS}

É de conhecimento que a Astronomia não é caracterizada como uma disciplina específica em qualquer etapa da Educação Básica, porém seus conteúdos perpassam diversas disciplinas e até estrutura-se em um conteúdo nos Anos Iniciais do Ensino Fundamental. Sendo assim, é inegável a relevância de tais conteúdos e que a falta deles pelo e para o professor acusa um trabalho precário dessa Ciência.

É evidente que a formação dos professores nas instituições de Ensino Superior é falha porque não se são abordados os conceitos específicos de Astronomia, o que caracteriza professores inseguros e despreparados, potencializando um fraco ensino nos Anos Iniciais do Ensino Fundamental.

Uma das formas para suprir essa defasagem é a inclusão de tópicos de noções de Astronomia durante a formação inicial dos professores e, sendo esta o curso de Pedagogia, é necessário que haja um trabalho constante da visão de Ciência não fragmentada e a apreciação da formação docente específica para a Ciência nas instituições de Ensino Superior. Além, do incentivo da formação continuada como cursos de extensão e/ou oficinas que capacitem e sanem lacunas para que esses profissionais trabalharem tanto o conteúdo específico quanto as estratégias metodológicas para tal conteúdo e busquem resultar em um ensino efetivo de Astronomia. 


\title{
A qualitative analysis of the basic Astronomy concepts of teachers from Elementary School
}

\begin{abstract}
The research consist in analyze quantitatively the basic Astronomy concepts of teachers from Elementary School of some private schools in Maringá, PR, based in a questionnaire made by the researchers. Afterward, the survey was forwarded to several elementary teachers. The work intend to highlight some concepts that are required in the curriculum, according to the municipal legislation, besides of describing some concepts that teachers should teach from specific aspects of their formation, according to answers in the questionnaire. The data gathered were put through content analysis (BARDIN,2000) and separeted in two Units of Meaning; the first concerns about the knowledge of the teacher regarding the study of Astronomy and their formation and the second focus in specific aspects of Astronomy. The analysis concluded that no teacher had some kind of specific training in the field. It is important to emphasize the little knowledge of the participants about Astronomy, especially when discussed about the rotation e translation of Earth as well as shown in the questionnaire, in specific regarding their initial formation, considered weak or almost null, of these professionals about Astronomy. It seems that the problems regarding the teachers' formation reflects daily in their classes, therefore, it is recommended that during the graduation the future teacher be presented to a critical analysis about Astronomy and seek to overcame their common sense.
\end{abstract}

KEYWORDS: Astronomy. Teachers' Formation. Elementary School. 


\section{AGRADECIMENTOS}

Agradecemos aos participantes e a CAPES.

\section{REFERÊNCIAS}

BARDIN, L. Análise de conteúdo. Lisboa: Edições 70, 2000.

BATISTA, M. C. Um estudo sobre o ensino de astronomia na formação inicial de professores dos anos iniciais. 2016. 183 p. Tese (Doutorado em Educação em Ciências e para a Matemática). UEM. Maringá.

BRASIL. Lei de Diretrizes e Bases da Educação Nacional. Lei 4024/1961.

Disponível em: <http://www2.camara.leg.br/legin/fed/lei/1960-1969/lei-402420-dezembro-1961-353722-publicacaooriginal-1-pl.html>. Acesso em: $10 \mathrm{abr}$. 2017.

GUELLERE, F. C. MACHADO, D. I. Astronomia no curso de pedagogia: condições e possibilidades. In: Encontro Nacional de Astronomia. 13. 2010. Recife. Disponível em: <http://www.sociedadeastronomica.com.br/enast/localizacao.php $>$. Acesso em: 10 abr. 2017.

Lei de Diretrizes e Bases da Educação Nacional. Lei 5692/1971.

Disponível em: <http://www2.camara.leg.br/legin/fed/lei/1970-1979/lei-569211-agosto-1971-357752-publicacaooriginal-1-pl.html>. Acesso em: 10 abr. 2017.

Lei de Diretrizes e Bases da Educação Nacional. Lei 9394/1996.

Disponível em: <http://www.planalto.gov.br/ccivil_03/leis/L9394.html>. Acesso em: 10 abr. 2017.

Plano Nacional de Educação - PNE/Ministério da Educação. Brasília, DF: INEP, 2001. Lei 10172/2001. Disponível em: <http://portal.mec.gov.br/arquivos/pdf/L10172.pdf>. Acesso em: 10 abr. 2017.

LANGHI, R. Ensino de Astronomia: erros conceituais mais comuns presentes em livros didáticos de ciências. Caderno Brasileiro de Ensino em Física, v. 24, n. 1: p. 87-111, abr. 2007.

MARINGÁ. Resolução no 170, de 2005. Aprova o “O novo projeto pedagógico do curso de graduação em pedagogia - habilitação: licenciatura. Disponível em: <http://www.scs.uem.br/2005/cep/170cep2005.htm>. Acesso em: 10 abr. 2017. 
MARINGÁ. Secretaria de educação. Currículo da Educação Infantil e Anos Iniciais do Ensino Fundamental. Maringá, PR, 2012. 444 p. Disponível em:

<http://www2.maringa.pr.gov.br/sistema/arquivos/3c1871b9202b.pdf>. Acesso

em: 10 abr. 2017.

PARANÁ. SEED. Ensino Fundamental de nove anos: orientações pedagógicas para os Anos Iniciais. Curitiba, PR, 2010. 176 p. Disponível em:

<http://www.klcconcursos.com.br/apoio/2a374359a9e0554c5eac2522946624ac. pdf >. Acesso em: 10 abr. 2017.

VALADARES, J. A. C. S. Concepções alternativas no ensino da física à luz da filosofia da ciência. Tese (Doutorado em Ciências da Educação). 1995. 821 f. Universidade Aberta, Lisboa, 1995.

Recebido: 29 mai. 2017

Aprovado: 21 jul. 2017

DOI: $10.3895 /$ actio.v2n1.6776

Como citar:

SILVA, A. H.; TRINTIN, R. da S. Uma análise qualitativa dos conceitos básicos de Astronomia dos

professores dos Anos Iniciais do Ensino Fundamental. ACTIO, Curitiba, v. 2, n. 1, p. 304-320, jan./jul. 2017.

Disponível em: <https://periodicos.utfpr.edu.br/actio>. Acesso em: XXX.

Correspondência:

Alisson Henrique Silva

Rua José Bergamasco, 135 A, Jd. Santa Alice, Maringá, Paraná, Brasil.

Direito autoral: Este artigo está licenciado sob os termos da Licença CreativeCommons-Atribuição 4.0

Internacional.

(c) (i) 